\title{
High host densities dilute sea lice Lepeophtheirus salmonis loads on individual Atlantic salmon, but do not reduce lice infection success
}

\author{
Francisca Samsing $^{1, *}$, Frode Oppedal ${ }^{2}$, David Johansson $^{2}$, Samantha Bui ${ }^{1}$, \\ Tim Dempster ${ }^{1,3}$
}

\author{
${ }^{1}$ Sustainable Aquaculture Laboratory - Temperate and Tropical (SALTT), Department of Zoology, University of Melbourne, \\ 3010 Victoria, Australia \\ ${ }^{2}$ Institute of Marine Research, 5984 Matredal, Norway \\ ${ }^{3}$ Centre for Research-based Innovation in Aquaculture Technology (CREATE), SINTEF Fisheries and Aquaculture, \\ 7465 Trondheim, Norway
}

\begin{abstract}
Host density likely plays a key role in host-parasite interactions, but empirical evidence in marine ecosystems remains limited. Classical models predict a positive relationship between host density and parasite infection parameters, but this depends on the parasite transmission mode. Evidence from systems where mobile parasites actively seek hosts suggests that numbers of parasites per host decrease with increasing host density ('dilution effect'). Copepodids, the infective stage of the salmon louse Lepeophtheirus salmonis, are mobile larvae that display a range of behaviours to detect their salmonid hosts. We hypothesized that high host density would decrease infection intensity, prevalence and degree of aggregation, but not infection success, which reflects parasite performance. We infected multiple groups of Atlantic salmon Salmo salar post-smolts at low (12 fish; $7.9 \mathrm{~kg} \mathrm{~m}^{-3}$ ) and high (96 fish; $68.5 \mathrm{~kg} \mathrm{~m}^{-3}$ ) densities, with the same number of $L$. salmonis copepodids in swimming chambers to enable more realistic swimming behaviours during infection. Infection intensity was 8.4 times higher in the low density treatment, but there were no differences in infection success and degree of aggregation. We observed $100 \%$ prevalence in the low density treatment, which was significantly higher than the high density treatment (68\%). The dilution effect most likely explained the negative relationship between host density and infection intensity, as the individual risk of being 'attacked' by a parasite decreased as host density increased. Host density is crucial in salmon-sea lice infection dynamics, and opportunities may exist within production environments to use the dilution effect of density to improve fish welfare outcomes.
\end{abstract}

KEY WORDS: Stocking density $\cdot$ Swimming speed $\cdot$ Parasite $\cdot$ Salmo salar

\section{INTRODUCTION}

Host density is a fundamental cornerstone of epidemiological theory and disease dynamics (Anderson \& May 1991), but compelling experimental evidence is still scarce (Côté \& Poulin 1995, Lloyd-Smith et al. 2005). Classical models (Anderson \& May 1978, 1979) predict that the mean number of parasites per

\footnotetext{
${ }^{*}$ Corresponding author: samsing@student.unimelb.edu.au
}

host (i.e. infection intensity) increases with higher host densities, due to the higher probability of encountering a host (Arneberg et al. 1998). However, examples of negative correlations between infection intensity and host density exist (McCallum et al. 2001). Exceptions are found in host-parasite systems where parasites encounter a limited number of hosts that they can attack per unit of time. Thus, larger

() The authors 2014. Open Access under Creative Commons by Attribution Licence. Use, distribution and reproduction are unrestricted. Authors and original publication must be credited. 
groups of hosts dilute the individual risk of being parasitized, a phenomenon termed the 'dilution effect' (Mooring \& Hart 1992, Hart 1994). Côté \& Poulin (1995) found that the direction of effect of host density upon infection intensity was governed by parasite transmission mode. As such, the relationship between host density and mean number of parasites per host is positive for contagious or directly transmitted agents (transmitted through close proximity between hosts or through infected faeces), and generally negative for mobile parasites which actively seek their host.

Sea lice Lepeophtheirus salmonis and Caligus spp. are external parasites responsible for multi-million dollar losses in the salmon industry worldwide (Costello 2009a), and for some of the major ecological impacts associated with marine aquaculture (Krkošek et al. 2007, Costello 2009b, Torrissen et al. 2013). Sea lice have a multiple-stage life cycle which includes free-swimming larvae and attached moult stages. Larval nauplii and copepodid stages disperse with water currents and seek potential hosts. When a host is encountered, the lice attach and move into the fixed chalimus stage (Bron et al. 1991). Lice become mobile in the pre-adult and adult stages, and freely move around their host (Morton et al. 2004, Hamre et al. 2013) or transfer to other hosts when searching for mates.

Copepodids, the mobile infective stage of L. salmonis, can alter their position in the water column in response to environmental variables (Heuch et al. 1995, Tucker et al. 2000, Bricknell et al. 2006) and actively seek their host (Heuch et al. 2007, Mordue Luntz \& Birkett 2009). As mobile parasites, an increase in host density could result in a lower infection intensity. Few studies have tested this empirically (Arneberg et al. 1998, Krasnov et al. 2002), particularly in aquatic systems (Sasal 2003), where disease epidemiology is qualitatively different from terrestrial systems (McCallum et al. 2004). Infection success (Sevatdal 2001), prevalence (Krasnov et al. 2002, Costello 2006) and degree of aggregation (Bagge et al. 2005, Stanko et al. 2006, Krasnov et al. 2007) also describe parasite infestation dynamics. Infection success is the proportion of parasites that successfully infect a host out of the total number of parasites available per host during infection (i.e. infective dose) and reflects parasite performance (Poulin \& FitzGerald 1989). Prevalence is the proportion of infected hosts and is expected to increase with host density due to an increased probability for a parasite to encounter a host. However, empirical studies in terrestrial systems (Morand \& Guégan 2000, Šimková et al. 2002) have indicated a positive correlation between prevalence and mean number of parasites per host, hence prevalence would be higher at low host densities for mobile parasites. Degree of aggregation refers to the parasite distribution among individuals within a group of hosts (Ives 1991) and is positively correlated with prevalence (Stanko et al. 2006). Together, previous evidence from other systems suggests that host density will influence most infection parameters in the salmon-sea lice, host-parasite system.

Most artificial infection protocols using sea lice only partially reflect how infection typically occurs in the ocean for both wild and farmed fish. Artificial infections add sea lice copepodids to tanks containing fish where water flow is turned off for several hours (Grimnes \& Jakobsen 1996, Dawson et al. 1997 , Bjørn \& Finstad 1998, Hull et al. 1998, Bowers et al. 2000, Mustafa et al. 2000, Tucker et al. 2000), or place anaesthetized fish in a concentrated suspension of sea lice copepodids (Bricknell et al. 2006, Øverli et al. 2014). The static water conditions during artificial infections or immobile fish contrast with natural infection settings for both farmed and wild salmon, where water currents may change infection dynamics (Revie et al. 2003). Here, we used swimming chambers with a fixed current speed that reflected the normal swimming speeds of salmon in farmed (Oppedal et al. 2011a) and wild environments (Thorstad et al. 2012). This enabled more realistic swimming behaviours during infection to test how host density influences infection intensity, infection success, prevalence and degree of aggregation of sea lice $L$. salmonis on Atlantic salmon (Fig. 1).

We hypothesized that high host density would result in a lower infection intensity, but similar infection success to low host density. High host density would increase salmon-sea lice encounter rates, but the higher infection dose at low host density would also favour encounters, thus infection success would be similar between density treatments. Further, we hypothesized that the dilution effect of high host density would decrease prevalence and degree of aggregation. Finally, we predicted that prevalence and infection intensity, and degree of aggregation and infection intensity, would be positively correlated.

\section{MATERIALS AND METHODS}

\section{Location and experimental setup}

We conducted the experiment at the Matre research station of the Institute of Marine Research, Norway. 


\section{Host Density}

\begin{tabular}{|c|c|}
\hline High & Low \\
\hline $\begin{array}{l}\text { Dilution effect: } \\
\downarrow \text { Infection intensity }\end{array}$ & $\begin{array}{l}\text { Dilution effect: } \\
\uparrow \text { Infection intensity }\end{array}$ \\
\hline$\downarrow$ Prevalence & $\uparrow$ Prevalence \\
\hline$\downarrow$ Degree of aggregation & $\uparrow$ Degree of aggregation \\
\hline $\begin{array}{l}\text { Parasites' performance: } \\
\sim \text { Infection success }\end{array}$ & $\begin{array}{l}\text { Parasites' performance: } \\
\sim \text { Infection success }\end{array}$ \\
\hline
\end{tabular}

Fig. 1. Predicted effects of differing host densities on infection parameters. Infection intensity is the mean number of sea lice per fish. Prevalence is the proportion of infected fish. Degree of aggregation refers to the parasite distribution among host individuals, and was assessed using Ives' (1991) measure of intraspecific aggregation $J$, defined as $J_{A}=V_{A} / N^{2}-1 / N$, where $V_{A}$ is the variance, and $N$ is the mean number of sea lice per fish. Infection success is the percent of infection intensity out of the total number of parasites available per host during infection (i.e. infective dose). We hypothesized that high host density will decrease infection intensity, prevalence and degree of aggregation due to the 'dilution effect', but would have no effect on infection success, a parameter that reflects parasite performance

For the trial, we used a set of tanks (3.0 m long $\times$ $0.75 \mathrm{~m}$ deep, volume $\sim 5 \mathrm{~m}^{3}$; see the Appendix), each holding a swimming chamber, or raceway. Cylindrical raceways were $0.35 \mathrm{~m}$ in diameter and $2.25 \mathrm{~m}$ long, with an internal volume of $0.2 \mathrm{~m}^{3}$. A laminar current speed of $16.2 \pm 0.5 \mathrm{~cm} \mathrm{~s}^{-1}$ (mean \pm $\mathrm{SE})$, equivalent to a swimming speed of 0.7 body lengths (BL) $\mathrm{s}^{-1}$, was generated in the raceways by a propeller (Minn Kota RT80/EM, Johnson Outdoors Marine Electronics) with adjustable speed followed by a honeycomb (5 mm opening, $102 \mathrm{~mm}$ thick, PC 5.0 G4, Plascore). Current speed was measured with a Vectrino velocimeter (Nortek) and was set at this level to reflect typical daytime swimming speeds of salmon (Oppedal et al. 2011a, Thorstad et al. 2012). Underwater video cameras (SeaVision SV27) were mounted in the middle of each raceway, with the field of view covering the back of the raceway. Water temperature during experiments was $13^{\circ} \mathrm{C}$, salinity $34 \%$ and dissolved oxygen concentration above $80 \%$ air saturation throughout the infection period. Each raceway was continuously illuminated (24:0 L:D regime) by a $36 \mathrm{~W}$ fluorescent tube suspended $35 \mathrm{~cm}$ above the water surface.

\section{Experimental fish}

We used Atlantic salmon Salmo salar post-smolts (Aquagen strain) which weighed on average $139.9 \pm$ $10.1 \mathrm{~g}$ (mean $\pm \mathrm{SE}$ ) and were $23.2 \pm 0.5 \mathrm{~cm}$ long (fork length). Prior to infection, fish were acclimatized in the raceways for $12 \mathrm{~h}$. During sampling, individuals were collected with a hand net, culled with a rapid blow to the head and placed in individual plastic bags to be analysed for the presence of sea lice.

\section{Experimental design}

To test the effect of host density on infection intensity (mean number of sea lice fish ${ }^{-1}$ ), infection success $(\%$ infection success $=$ infection intensity $\times 100 /$ infective dose), prevalence (proportion of infected fish) and degree of aggregation within the group of fish, we randomly allocated 96 fish to each high density treatment replicate and 12 fish to each low density treatment replicate, and infected both with the same estimated amount of infective copepodids.

Based on fish size, densities were $7.9 \pm 1.0 \mathrm{~kg} \mathrm{~m}^{-3}$ and $68.5 \pm 5.8 \mathrm{~kg} \mathrm{~m}^{-3}$ in the low and high density treatments, respectively. These densities reflect realistic swimming densities experienced by farmed salmon in sea-cages (Oppedal et al. 2011a,b). While stocking density (total biomass of fish divided by cage volume) is typically 5 to $25 \mathrm{~kg} \mathrm{~m}^{-3}$, swimming density is driven by fish actively choosing specific depths based on environmental preferences (Oppedal et al. 2011a). Swimming densities are typically 1.5 to 5 times the stocking densities, thus our 2 densities sit well within the lower and upper bounds of known swimming densities (0 to $190 \mathrm{~kg} \mathrm{~m}^{-3}$; Oppedal et al. 2011b).

We conducted the experiment in blocks to complete 4 replicates for each density treatment, and 10 fish were sampled $48 \mathrm{~h}$ after the start of the infection to calculate the average data used for each replicate. The degree of aggregation was assessed using Ives' (1991) measure of intraspecific aggregation $J_{\text {, }}$ defined as:

$$
J_{A}=V_{A} / N^{2}-1 / N
$$

where $V_{A}$ is the variance, and $N$ is the mean number of sea lice fish ${ }^{-1}$ in each replicate. $J$ is the increase in the expected number of parasites that infect an average host above the number that would be expected by chance if parasites were randomly distributed among hosts. When $J>0$, parasites are aggregated, and when $J=0$ they are randomly dispersed. 


\section{Infection protocol}

To source the sea lice copepodids that we used for our experiments, we infected a separate group of 30 salmon with pre-adult II and adults of Lepeophtheirus salmonis collected from a farm in Solheim, west coast of Norway. Fish were kept at $14^{\circ} \mathrm{C}$ until female lice extruded egg strings, which were dissected and incubated in aquaria with a constant flow of seawater at $15^{\circ} \mathrm{C}$ for $5 \mathrm{~d}$ until the development of infective copepodids. Copepodid number was calculated indirectly by counting them in a $25 \mathrm{ml}$ aliquot. An estimate of 1000 copepodids was used to infect both treatments. During infection, the sea lice suspension was added to the tanks, and the inflow of water was stopped for $1 \mathrm{~h}$ to allow the larvae to recirculate, but the constant current inside the raceways kept the fish swimming normally. After the first hour, normal inflow was restored until sampling. Sampled fish were analysed for the presence of sea lice, to record total number and their location on the body surface (including gills) and the fins.

\section{Swimming behaviours}

Behavioural differences between fish at different densities could explain variations in infection parameters. Behavioural observations were made before and during infection using underwater cameras, and tanks were videotaped for a $10 \mathrm{~min}$ period each time. The video recording, and thus the behavioural monitoring, was done before and immediately after introducing the infective sea lice copepodids into the tanks. We recorded the total number of jumps, bursts, rolls and muscle twitches on 5 randomly selected fish from the third quarter of the raceway (i.e. readily visible individuals). We observed each individual for $2 \mathrm{~min}$ (Altmann 1974). Jumps were defined as fast acceleration in swimming speed that ended in a jump and contact with the surface; bursts were fast accelerations in swimming speed performed against the current, without contact with the surface; rolls involved turning $90^{\circ}$ on the horizontal or vertical plane, and swimming in that position, without fast acceleration; and muscle twitches were rapid spasmodic contractions of the body, without relocation of more than 0.5 BL.

\section{Statistical analysis}

Differences in infection intensity, infection success, prevalence and degree of aggregation between den- sity treatments were compared with 1-way ANOVAs. Infection intensity was log-transformed to improve normality. Multiple transformations on the other parameters did not markedly improve normality. We calculated Pearson's correlation coefficient to explore the relationship between log mean sea lice fish $^{-1}$ and both prevalence and degree of aggregation using the data from each replicate in both treatments. We calculated the proportion of sea lice attached to the body surface (including the gills) and the fins, and compared these proportions using 1-way ANOVAs. These proportions were calculated by dividing the total number of sea lice attached to a body region by the total number of sea lice attached to the sampled fish in each replicate. For the behavioural analysis, differences in counts of behaviours (i.e. jumps, bursts, rolls and muscle twitches) between treatments before infection, and differences between treatments during infection were compared with 1-way ANOVAs. We compared the differences in counts of behaviours before and during infection, pooling over the effect of treatment, using paired $t$-tests. Test assumptions of normality and homogeneity of variance were evaluated by assessing box plots and plots of model residuals.

\section{RESULTS}

Sea lice infection intensity differed between the 2 density treatments; low density had 8.4 times more lice per fish than high density $\left(F_{1,6}=26, \mathrm{p}=0.001\right.$; Fig. 2), which matches the 8 times more fish in the high density. However, there were no differences in
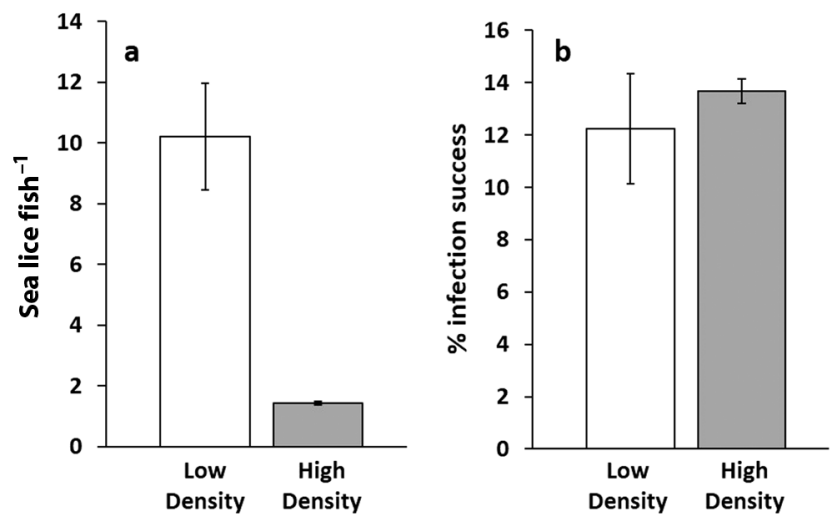

Fig. 2. Mean \pm SE (a) sea lice Lepeophtheirus salmonis per salmon Salmo salar and (b) infection success (percent of infection intensity) after infection at low (12 fish; $7.9 \pm 1.0 \mathrm{~kg}$ $\mathrm{m}^{-3}$, mean $\pm \mathrm{SE}$; open bars) and high (96 fish; $68.5 \pm 5.8 \mathrm{~kg}$ $\mathrm{m}^{-3}$; grey bars) fish densities 

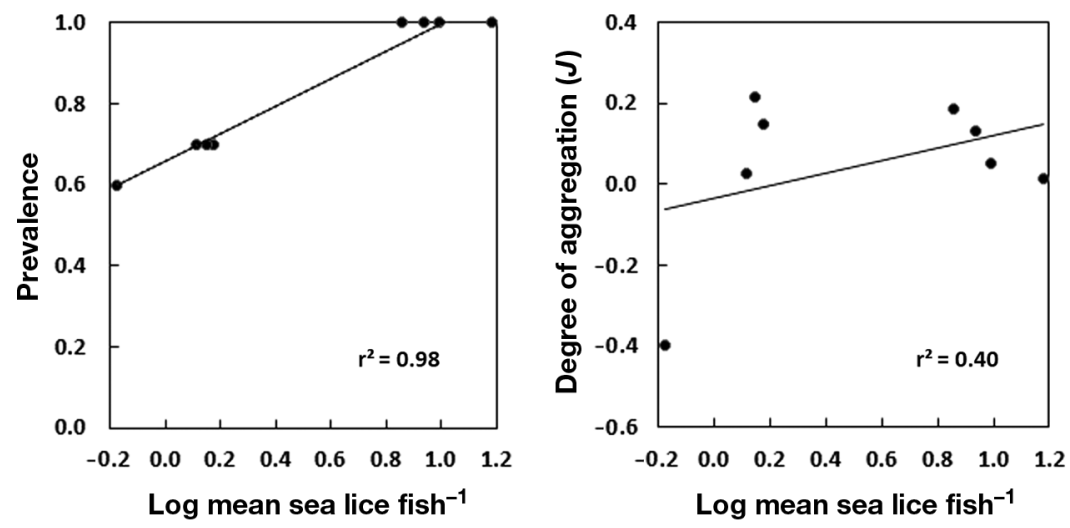

Fig. 3. Correlations between prevalence and log mean sea lice Lepeophtheirus salmonis per salmon Salmo salar, and degree of aggregation and $\log$ mean sea lice fish ${ }^{-1}$

infection success $\left(F_{1,6}=0.04, \mathrm{p}=0.8\right)$, which was approximately $12 \%$ in both treatments, and no differences in the proportion of sea lice copepodids attached to the body $\left(F_{1,6}=0.98, \mathrm{p}=0.36\right)$ and the fins $\left(F_{1,6}=0.98, \mathrm{p}=0.36\right)$. Prevalence differed significantly between density treatments $\left(F_{1,6}=169, \mathrm{p}<\right.$ $0.001)$; all low density replicates had a prevalence of 1 (i.e. all sampled fish were infected), whereas the high density treatment had an average prevalence of $0.68 \pm 0.03$ (mean $\pm \mathrm{SE}$ ). All $J$ values were low (low density: $0.10 \pm 0.04$; high density: $0.00 \pm 0.14$ ), indicating that parasites were to some extent aggregated, but the degree of aggregation did not vary between treatments $\left(F_{1,6}=0.47, \mathrm{p}=0.52\right)$. Log mean sea lice fish $^{-1}$ and prevalence were strongly correlated (Pearson's correlation: $\mathrm{r}^{2}=0.98$ ), with a weaker correlation between log mean sea lice fish ${ }^{-1}$ and degree of aggregation $\left(r^{2}=0.40 ;\right.$ Fig. 3). Data from the low density treatment was normally distributed (AndersonDarling $=0.5 ; \mathrm{p}=0.2$ ), whereas infection intensity from fish in the high density level fitted a Poisson distribution $\left(\chi^{2}=0.8 ; p=0.7\right)$.

Before infection, the total count of behaviours was higher in the low density treatment $\left(3\right.$ times, $F_{1,6}=$ 14.7, $\mathrm{p}=0.009$ ). More bursts (3.2 times, $F_{1,6}=21, \mathrm{p}=$ $0.004)$ were observed during infection in the low density treatment, but there were no significant differences between density levels in the other behaviours and in the total count of behaviours during infection $\left(F_{1,6}=21, \mathrm{p}=0.004 ;\right.$ Fig. 4$)$.

\section{DISCUSSION}

Here, we tested how host density influences sea lice infection parameters on Atlantic salmon, and have demonstrated that high host density reduces the mean number of sea lice copepodids per host after infection. Similar outcomes have been reported for sticklebacks (Poulin \& FitzGerald 1989), lizards (Sorci et al. 1997) and reindeer (Fauchald et al. 2007), whereby larger group sizes decrease infection intensity. Grouping or shoaling in fish is widely recognized as an anti-predator mechanism that exerts its effect through the dilution of the individual risk of being eaten (Pitcher \& Parrish 1993, Chivers et al. 1995). The term 'dilution effect' was initially introduced by Hamilton (1971) for predator-prey interactions, but the term has also been used to define hostparasite interactions (Schmidt \& Ostfeld 2001), where the increase in host density reduces the per capita parasite load. The relationship between host density and infection intensity appears to depend on the transmission mode of the parasite (Côté \& Poulin 1995). Sea lice copepodids are mobile crustaceans (Pike \& Wadsworth 1999, Bricknell et al. 2006), which actively seek their host and display a range of hostfinding behaviours when they detect host-related cues (Heuch et al. 2007, Mordue Luntz \& Birkett 2009). Mobile parasites searching for a host are analogous to predators seeking their prey, and similarly the probability of an individual host being 'attacked'

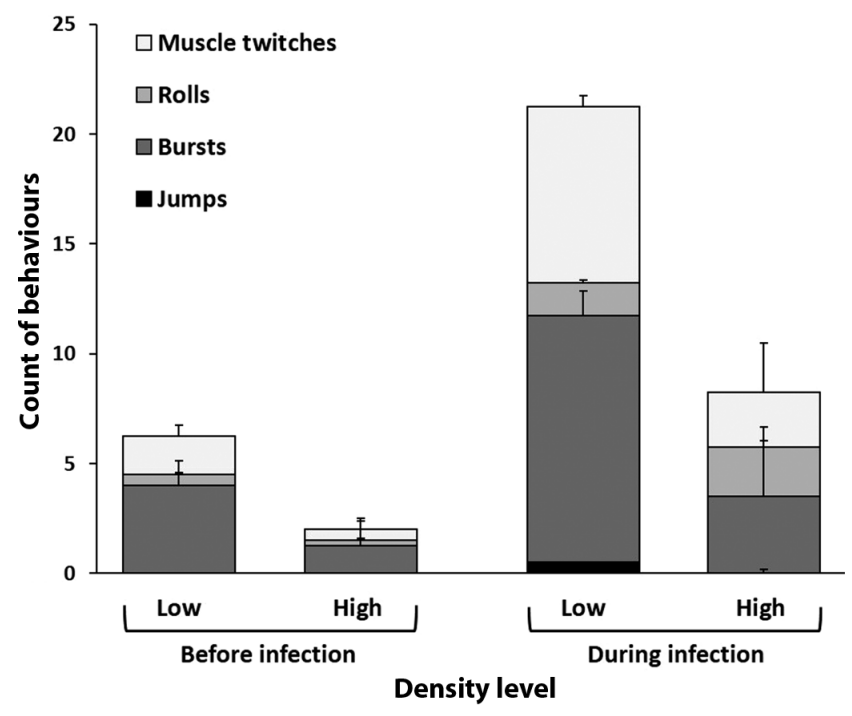

Fig. 4. Mean \pm SE count of behaviours (muscle twitches, rolls, bursts, jumps) observed in salmon Salmo salar before and during infection with sea lice Lepeophtheirus salmonis copepodids at low (12 fish; $7.9 \pm 1.0 \mathrm{~kg} \mathrm{~m}^{-3}$, mean $\pm \mathrm{SE}$ ) and high (96 fish; $68.5 \pm 5.8 \mathrm{~kg} \mathrm{~m}^{-3}$ ) fish densities 
decreases with group size. Therefore, the same 'dilution effect' that reduces predation in groups of prey would reduce sea lice infection intensity in groups of salmon at high densities.

In host-parasite interactions, the term 'dilution effect' was originally applied to the prevalence of a disease. Ostfeld \& Keesing (2000) demonstrated that increasing host density would reduce infection prevalence, and therefore dilute the risk of vectorborne zoonoses. Here, we show that high fish density diluted sea lice prevalence in a group of Atlantic salmon post-smolts, an outcome that has been demonstrated for other host-parasite interactions in terrestrial systems (Krasnov et al. 2002, 2007). However, overall infection success remained unchanged at $12 \%$ in both density treatments; hence parasite performance was not affected by fish density.

In most host-parasite interactions, the question of whether infection parameters and their correlations are characteristic (= repeatable) of a particular parasite species is commonly addressed (Poulin 2006, Krasnov et al. 2007). We detected a strong positive correlation between sea lice infection intensity and prevalence, and a weaker positive correlation with degree of aggregation, but no differences between density treatments for this last parameter. The strong positive correlation between prevalence and infection intensity has been demonstrated previously for Lepeophtheirus salmonis on both wild (Heuch et al. 2011) and farmed salmon (Baillie et al. 2009), suggesting a characteristic pattern of infestations. We detected a modest degree of aggregation, even though sea lice infestations in both wild and farmed salmon are generally aggregated (Costello 2006), and this pattern is characteristic of this parasite species (Heuch et al. 2011). Therefore, our low degree of aggregation could be an artefact of experimental infections, which tend to be more homogeneous than natural ones (Costello 2006). For mobile parasites, prevalence is positively correlated to degree of aggregation, and therefore the latter is also positively correlated to infection intensity (Stanko et al. (2006); we also detected these relationships.

Sea lice distribution among hosts is related to prevalence, with a close fit to a negative binomial distribution at low prevalence levels $(<20 \%)$, a Poisson distribution at higher prevalence levels $(70 \%)$, and close to normal as prevalence approaches $100 \%$ (Heuch et al. 2011), which aligns with our results. Infection intensity can be estimated from prevalence values and the negative binomial distribution that characterizes most sea lice infestations (Baillie et al. (2009). Consequently, as recording prevalence (pres- ence or absence of a louse type) is far easier than counting exact lice abundance, using a broader sampling strategy to estimate prevalence combined with a more limited intensive sampling to estimate abundance, could provide a more accurate double metric to estimate infection intensity (Baillie et al. 2009), which is a mandatory process in salmon farms in salmon-producing countries (Heuch et al. 2011). Moreover, as sea lice infestations are usually aggregated, traditional sampling protocols used to calculate sea lice infection intensities in farms (e.g. sample 20 fish from 2 cages) may not give representative values of the mean number of sea lice fish ${ }^{-1}$ in a particular site or farm. Hence, calculating prevalence to estimate mean number of sea lice fish $^{-1}$ could allow larger sample sizes from more sites or cages, improving the precision of sea lice surveillance protocols.

Behaviour is considered the first line of defence against parasitism, and hosts normally display an array of anti-parasite behaviours (Hart 1990, Barber $\&$ Rushbrook 2008). The main purpose of measuring behaviour in our study was to determine whether differences in behavioural dynamism between density treatments would explain variations in infection parameters. Fish in the high density treatment showed fewer behavioural displays than fish at low densities before infection; the more limited space available to individuals in the higher density appears to have reduced the expression of specific behaviours. However, in both treatments, the frequency of observed behaviours increased during infection, with only bursts being more prevalent in the low density treatment. This increase in behavioural dynamism could be a reaction to the presence of sea lice copepodids, or an evolved behaviour to evade them. Changes in behaviour of fish exposed to ectoparasitic copepods have been reported previously for Atlantic salmon exposed to L. salmonis (Webster et al. 2007) and brook trout exposed to Salmincola edwarsii (Poulin et al. 1991). However, determining whether these behaviours effectively reduce infestations requires further study. As major differences in behaviour did not exist between density treatments during infection, we assume that fish in both treatments were able to broadly display their behaviours. Both treatments had similar infection success, thus we can assume that neither density nor behaviour are affecting parasite performance. Further, behaviour could be a mechanism to deflect the body location of attached ectoparasites on a host (e.g. Sears et al. 2013). However, the proportion of copepodids attached to the body or the fins did not differ between treatments, further supporting the assumption that fish in high 
and low densities could manifest their behaviours without restrictions.

Stocking density of farmed fish is a central topic in aquaculture, and various studies have examined its effect on fish welfare. For example, Arctic charr Salvelinus alpinus show fewer agonistic behaviours and higher growth rates at high stocking densities (Brown et al. 1992). Similarly, Adams et al. (2007) demonstrated that aggressive interactions were negatively related to stocking density in Atlantic salmon, and their overall welfare score was best at an intermediate density of $25 \mathrm{~kg} \mathrm{~m}^{-3}$, indicating that both low and high densities may affect welfare. If densities become too high, oxygen depletion becomes problematic (Oppedal et al. 2011b), and environmental hypoxia may reduce salmon welfare. Moreover, studies generally use absolute stocking densities (i.e. based on total biomass), which seldom reflect the actual fish density inside the cage as fish choose to congregate at specific depths depending on environmental conditions (Oppedal et al. 2011a). For farmed Atlantic salmon, swimming densities typically exceed stocking densities by 1.5 to 5 times, and up to 17 times in specific environments (Oppedal et al. 2011a,b), and this has to be considered when planning strategic procedures to improve welfare at the farm level.

Combined with an understanding of sea lice loads in the water column and environmental data, our results could be useful in opening new strategies to improve farmed salmon welfare. Salmon swimming behaviour and their vertical position in the water column is strongly influenced by light levels (Tang et al. 2011), and can be manipulated by using artificial light (Juell et al. 2003, Oppedal et al. 2007, Frenzl et al. 2014). Sea lice copepodids are phototactic and gather near surface waters during the day, while also actively avoiding low salinities (Heuch et al. 1995, Costello 2006). Consequently, a combination of procedures to keep salmon away from parasite-risky areas in surface layers (F. Oppedal et al. unpubl.), and increase the swimming density of fish deeper in the cage to dilute the individual risk of being parasitized, could produce the best overall effect for salmon welfare in farming environments. Further, the observed behavioural change could be used as an operational welfare indicator giving the farmer an early warning.

Acknowledgements. We thank Marsela Alvanopoulou, Ole Fredrik Skulstad and Enrique García for technical assistance during the experiments. Funding was provided by the Norwegian Research Council through the project Exposed Salmon Farming in High Current and Waves (207116/E40) and Behaviour and Coping of Individual Salmon in Farm Environments with Fluctuating Oxygen and Hydrodynamics (206968). The work was conducted in accordance with the laws and regulations of the Norwegian Regulation on Animal Experimentation 1996 under permit number 6221.

\section{LITERATURE CITED}

Adams CE, Turnbull JF, Bell A, Bron JE, Huntingford FA (2007) Multiple determinants of welfare in farmed fish: stocking density, disturbance, and aggression in Atlantic salmon (Salmo salar). Can J Fish Aquat Sci 64:336-344

- Altmann J (1974) Observational study of behavior: sampling methods. Behaviour 49:227-267

Anderson RM, May RM (1978) Regulation and stability of host-parasite population interactions: I. Regulatory processes. J Anim Ecol 47:219-247

Anderson RM, May RM (1979) Population biology of infectious diseases: Part I. Nature 280:361-367

Anderson RM, May RM (1991) Infectious diseases of humans: dynamics and control. Oxford University Press, Oxford

Arneberg P, Skorping A, Grenfell B, Read AF (1998) Host densities as determinants of abundance in parasite communities. Proc R Soc Lond B Biol Sci 265:1283-1289

Bagge AM, Sasal P, Valtonen ET, Karvonen A (2005) Infracommunity level aggregation in the monogenean communities of crucian carp (Carassius carassius). Parasitology 131:367-372

Baillie M, Lees F, Gettinby G, Revie CW (2009) The use of prevalence as a measure of lice burden: a case study of Lepeophtheirus salmonis on Scottish Atlantic salmon, Salmo salar L., farms. J Fish Dis 32:15-25

Barber I, Rushbrook BJ (2008) Parasites and fish behaviour. In: Magnhagen C, Braithwaite VA, Forsgren E, Kapoor BG (eds) Fish behaviour. Science Publishers, Enfield, $\mathrm{NH}, \mathrm{p}$ 525-561

> Bjørn PA, Finstad B (1998) The development of salmon lice (Lepeophtheirus salmonis) on artificially infected post smolts of sea trout (Salmo trutta). Can J Zool 76:970-977

- Bowers JM, Mustafa A, Speare DJ, Conboy GA, Brimacombe M, Sims DE, Burka JF (2000) The physiological response of Atlantic salmon, Salmo salar L., to a single experimental challenge with sea lice, Lepeophtheirus salmonis. J Fish Dis 23:165-172

Bricknell IR, Dalesman SJ, O'Shea B, Pert CC, Mordue Luntz AJ (2006) Effect of environmental salinity on sea lice Lepeophtheirus salmonis settlement success. Dis Aquat Org 71:201-212

Bron JE, Sommerville C, Jones M, Rae GH (1991) The settlement and attachment of early stages of the salmon louse, Lepeophtheirus salmonis (Copepoda: Caligidae) on the salmon host, Salmo salar. J Zool (Lond) 224:201-212

Brown GE, Brown JA, Srivastava RK (1992) The effect of stocking density on the behaviour of Arctic charr (Salvelinus alpinus L.). J Fish Biol 41:955-963

Chivers DP, Brown GE, Smith RJ (1995) Familiarity and shoal cohesion in fathead minnows (Pimephales promelas): implications for antipredator behaviour. Can J Zool 73:955-960

> Costello MJ (2006) Ecology of sea lice parasitic on farmed and wild fish. Trends Parasitol 22:475-483

> Costello MJ (2009a) The global economic cost of sea lice to the salmonid farming industry. J Fish Dis 32:115-118

> Costello MJ (2009b) How sea lice from salmon farms may 
cause wild salmonid declines in Europe and North America and be a threat to fishes elsewhere. Proc R Soc Lond B Biol Sci 276:3385-3394

Côté IM, Poulin R (1995) Parasitism and group size in social animals: a meta-analysis. Behav Ecol 6:159-165

Dawson LHJ, Pike AW, Houlihan DF, McVicar AH (1997) Comparison of the susceptibility of sea trout (Salmo trutta L.) and Atlantic salmon (Salmo salar L.) to sea lice (Lepeophtheirus salmonis (Krøyer, 1837)) infections. ICES J Mar Sci 54:1129-1139

Fauchald P, Rødven R, Bårdsen BJ, Langeland K, Tveraa T, Yoccoz NG, Ims RA (2007) Escaping parasitism in the selfish herd: age, size and density-dependent warble fly infestation in reindeer. Oikos 116:491-499

Frenzl B, Stien LH, Cockerill D, Oppedal F and others (2014) Manipulation of farmed Atlantic salmon swimming behaviour through the adjustment of lighting and feeding regimes as a tool for salmon lice control. Aquaculture 424-425:183-188

> Grimnes A, Jakobsen PJ (1996) The physiological effects of salmon lice infection on post-smolt of Atlantic salmon. J Fish Biol 48:1179-1194

> Hamilton WD (1971) Geometry for the selfish herd. J Theor Biol 31:295-311

> Hamre LA, Eichner C, Caipang CMA, Dalvin ST and others (2013) The salmon louse Lepeophtheirus salmonis (Copepoda: Caligidae) life cycle has only two chalimus stages. PLoS ONE 8:e73539

Hart BL (1990) Behavioral adaptations to pathogens and parasites: five strategies. Neurosci Biobehav Rev 14: 273-294

> Hart BL (1994) Behavioural defense against parasites: interaction with parasite invasiveness. Parasitology 109: S139-S151

> Heuch PA, Parsons A, Boxaspen K (1995) Diel vertical migration: a possible host-finding mechanism in salmon louse (Lepeophtheirus salmonis) copepodids? Can J Fish Aquat Sci 52:681-689

Heuch PA, Heuch MH, Doall J, Yen J (2007) Water flow around a fish mimic attracts a parasitic and deters a planktonic copepod. J Plankton Res 29:i3-i16

> Heuch PA, Gettinby G, Revie CW (2011) Counting sea lice on Atlantic salmon farms-Empirical and theoretical observations. Aquaculture 320:149-153

Hull MQ, Pike AW, Mordue (Luntz) AJ, Rae GH (1998) Patterns of pair formation and mating in an ectoparasitic caligid copepod Lepeophtheirus salmonis (Krøyer 1837): implications for its sensory and mating biology. Philos Trans R Soc Lond B Biol Sci 353:753-764

> Ives AR (1991) Aggregation and coexistence in a carrion fly community. Ecol Monogr 61:75-94

> Juell JE, Oppedal F, Boxaspen K, Taranger GL (2003) Submerged light increases swimming depth and reduces fish density of Atlantic salmon Salmo salar L. in production cages. Aquacult Res 34:469-478

> Krasnov B, Khokhlova I, Shenbrot G (2002) The effect of host density on ectoparasite distribution: an example of a rodent parasitized by fleas. Ecology 83:164-175

Krasnov B, Stanko M, Morand S (2007) Host community structure and infestation by ixodid ticks: repeatability, dilution effect and ecological specialization. Oecologia 154:185-194

Krkošek M, Ford JS, Morton A, Lele S, Myers RA, Lewis MA (2007) Declining wild salmon populations in relation to parasites from farm salmon. Science 318:1772-1775
Lloyd-Smith JO, Cross PC, Briggs CJ, Daugherty $M$ and others (2005) Should we expect population thresholds for wildlife disease? Trends Ecol Evol 20:511-519

McCallum H, Barlow N, Hone J (2001) How should pathogen transmission be modelled? Trends Ecol Evol 16: 295-300

McCallum HI, Kuris A, Harvell CD, Lafferty KD, Smith GW, Porter J (2004) Does terrestrial epidemiology apply to marine systems? Trends Ecol Evol 19:585-591

> Mooring MS, Hart BL (1992) Animal grouping for protection from parasites: selfish herd and encounter-dilution effects. Behaviour 123:173-193

> Morand S, Guégan JF (2000) Distribution and abundance of parasite nematodes: ecological specialisation, phylogenetic constraint or simply epidemiology? Oikos 88: $563-573$

> Mordue Luntz AJ, Birkett MA (2009) A review of host finding behaviour in the parasitic sea louse, Lepeophtheirus salmonis (Caligidae: Copepoda). J Fish Dis 32:3-13

> Morton A, Routledge R, Peet C, Ladwig A (2004) Sea lice (Lepeophtheirus salmonis) infection rates on juvenile pink (Oncorhynchus gorbuscha) and chum (Oncorhynchus keta) salmon in the nearshore marine environment of British Columbia, Canada. Can J Fish Aquat Sci 61: 147-157

Mustafa A, MacWilliams C, Fernandez N, Matchett K, Conboy GA, Burka JF (2000) Effects of sea lice (Lepeophtheirus salmonis Kröyer, 1837) infestation on macrophage functions in Atlantic salmon (Salmo salar L.). Fish Shellfish Immunol 10:47-59

> Oppedal F, Juell JE, Johansson D (2007) Thermo- and photoregulatory swimming behaviour of caged Atlantic salmon: implications for photoperiod management and fish welfare. Aquaculture 265:70-81

Oppedal F, Dempster T, Stien LH (2011a) Environmental drivers of Atlantic salmon behaviour in sea-cages: a review. Aquaculture 311:1-18

> Oppedal F, Vågseth T, Dempster T, Juell JE, Johansson D (2011b) Fluctuating sea-cage environments modify the effects of stocking densities on production and welfare parameters of Atlantic salmon (Salmo salar L.). Aquaculture 315:361-368

> Ostfeld RS, Keesing F (2000) The function of biodiversity in the ecology of vector-borne zoonotic diseases. Can J Zool 78:2061-2078

○verli Ø, Nordgreen J, Mejdell CM, Janczak AM, Kittilsen S, Johansen IB, Horsberg TE (2014) Ectoparasitic sea lice (Lepeophtheirus salmonis) affect behaviour and brain serotonergic activity in Atlantic salmon (Salmo salar L.): perspectives on animal welfare. Physiol Behav 132:44-50

> Pike AW, Wadsworth SL (1999) Sealice on salmonids: their biology and control. Adv Parasitol 44:233-337

Pitcher TJ, Parrish JK (1993) Functions of shoaling behaviour in teleosts. In: Pitcher TJ (ed) The behaviour of teleost fishes. Chapman \& Hall, London, p 363-439

> Poulin R (2006) Variation in infection parameters among populations within parasite species: intrinsic properties versus local factors. Int J Parasitol 36:877-885

Poulin R, FitzGerald GJ (1989) Shoaling as an antiectoparasite mechanism in juvenile sticklebacks (Gasterosteus spp.). Behav Ecol Sociobiol 24:251-255

> Poulin R, Rau ME, Curtis MA (1991) Infection of brook trout fry, Salvelinus fontinalis, by ectoparasitic copepods: the role of host behaviour and initial parasite load. Anim Behav 41:467-476 
Revie CW, Gettinby G, Treasurer JW, Wallace C (2003) Identifying epidemiological factors affecting sea lice Lepeophtheirus salmonis abundance on Scottish salmon farms using general linear models. Dis Aquat Org 57:85-95

Sasal P (2003) Experimental test of the influence of the size of shoals and density of fish on parasite infections. Coral Reefs 22:241-246

Schmidt KA, Ostfeld RS (2001) Biodiversity and the dilution effect in disease ecology. Ecology 82:609-619

Sears BF, Snyder PW, Rohr JR (2013) Infection deflection: hosts control parasite location with behaviour to improve tolerance. Proc R Soc Lond B Biol Sci 280:20130759

Sevatdal S (2001) An improved method for experimental infection of salmon (Salmo salar L.) with salmon lice, Lepeophtheirus salmonis (Krøyer). Bull Eur Assoc Fish Pathol 21:109-113

Šimková A, Kadlec D, Gelnar M, Morand S (2002) Abundance-prevalence relationship of gill congeneric ectoparasites: testing the core satellite hypothesis and ecological specialisation. Parasitol Res 88:682-686

Sorci G, de Fraipont M, Clobert J (1997) Host density and ectoparasite avoidance in the common lizard (Lacerta vivipara). Oecologia 111:183-188

Stanko M, Krasnov B, Morand S (2006) Relationship be- tween host abundance and parasite distribution: inferring regulating mechanisms from census data. J Anim Ecol 75:575-583

- Tang S, Lewis AG, Sackville M, Nendick L, DiBacco C, Brauner CJ, Farrell AP (2011) Diel vertical distribution of early marine phase juvenile pink salmon (Oncorhynchus gorbuscha) and behaviour when exposed to salmon louse (Lepeophtheirus salmonis). Can J Zool 89:796-807

Thorstad EB, Whoriskey F, Uglem I, Moore A, Rikardsen AH, Finstad B (2012) A critical life stage of the Atlantic salmon Salmo salar: behaviour and survival during the smolt and initial post-smolt migration. J Fish Biol 81: $500-542$

Torrissen O, Jones S, Asche F, Guttormsen A and others (2013) Salmon lice-impact on wild salmonids and salmon aquaculture. J Fish Dis 36:171-194

- Tucker CS, Sommerville C, Wootten R (2000) The effect of temperature and salinity on the settlement and survival of copepodids of Lepeophtheirus salmonis (Krøyer, 1837) on Atlantic salmon, Salmo salar L. J Fish Dis 23:309-320

Webster SJ, Dill LM, Butterworth K (2007) The effect of sea lice infestation on the salinity preference and energetic expenditure of juvenile pink salmon (Oncorhynchus gorbuscha). Can J Fish Aquat Sci 64:672-680

Appendix. Schematic of the tank $\left(3 \mathrm{~m} \times 0.75 \mathrm{~m}\right.$ depth; volume $\left.\sim 5 \mathrm{~m}^{3}\right)$ holding the experimental raceway $\left(2 \mathrm{~m} \times 0.1 \mathrm{~m}^{2}\right.$ transsectional area; volume $\sim 0.2 \mathrm{~m}^{3}$ ) with underwater camera. Raceways were fitted with a propeller with adjustable speed followed by a honeycomb to generate the laminar flows

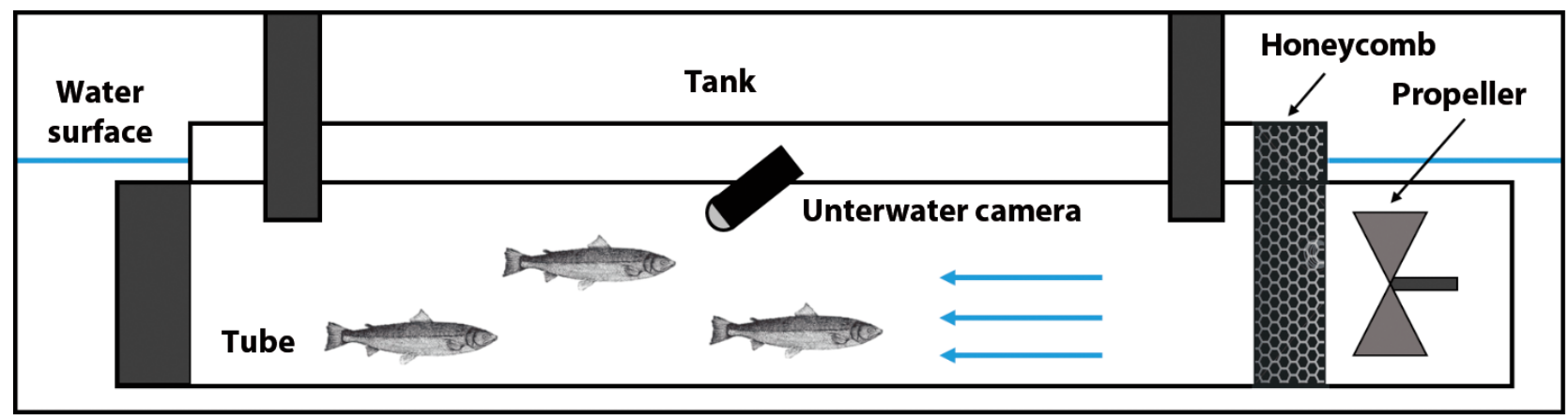

Editorial responsibility: Bengt Finstad, Trondheim, Norway
Submitted: August 1, 2014; Accepted: October 20, 2014

Proofs received from author(s): November 22, 2014 